\title{
Strategies of coping with situations of difficult pedagogical communication among teachers working in residential institutions
}

\author{
O. V. Zadorozhnaya ${ }^{1}$, V. V. Maiba ${ }^{1}$, E. N. Novokhat'ko ${ }^{2 *}$, N. In. Lomova ${ }^{3}$ \\ ${ }^{1}$ Rostov State Transport University, Rostov-on-Don, Russia \\ ${ }^{2}$ South Federal University, Department of Development Psychology, 344006 Rostov-on- \\ Don, Russia \\ ${ }^{3}$ Don State Technical University, 344000 Rostov-on-Don, Russian Federation
}

\begin{abstract}
Professional activity of teachers working in residential institutions is a special type of activity associated with the strengthening of the action of emotionogenic factors in connection with the specifics of the contingent of students and learning conditions, which often causes the syndrome of emotional burnout. The study conducted a comparative analysis of preferences in the choice of coping strategies, manifested in the success of overcoming situations of difficult pedagogical communication of teachers working in residential institutions and teachers of secondary schools. It is established that coping strategies chosen by respondents of experimental and control groups in situations of problematic communication in accordance with the stage of emotional burnout have qualitative differences: teachers working in residential institutions, at each stage often use coping avoidance and aggressiveness, teachers of secondary schools - coping assertiveness with a tendency to impulsiveness on the background of emotional response. The obtained results are relevant for the programs of prevention of professional burnout of teachers with the help of health-saving technologies and teaching them constructive strategies of coping with stressful professional situations.
\end{abstract}

In the research space of psychological and pedagogical knowledge for a long time actualized the need to study the various aspects of pedagogical activity, because of the importance and social significance of this profession for society as a whole, and for the formation of an individual. The most difficult pedagogical task is the organization of productive communication, involving the establishment of contact between the participants of the educational process, creating an atmosphere of understanding and trust, overcoming fears and concerns, high-level characteristics of the communicative competence of the teacher.

The phenomenal component of pedagogical communication in modern research is to determine the boundaries of the problem field of the phenomenon under study. In socio-

\footnotetext{
${ }^{*}$ Corresponding author: elenanovok@yandex.ru
} 
psychological studies, pedagogical communication is studied mainly in the context of a given situation of social interaction [1], the sociological approach focuses on the discrepancy between the goal and the result of the unfolding pedagogical situation from the chosen model of communication [1], psychological and pedagogical studies pay attention to the leading role of the relations of participants in the educational process, as well as subjective factors including experiences, unmet needs, conflicts [2], etc.

The reasons for difficulty of communication include: the presence of objective and subjective difficulties (level of group development, the psychological characteristics of its members, the presence of the triggers that starts the problem of pedagogical communication, etc.); social and physical causes generated by various psychogenic and sociogenetic influences contributing to communication difficulties; situational or stable factors of difficulties of communication; age and gender; personal; cognitive (ideas, opinions, stereotypes), behavioral, motivational, reactive, instrumental (communication skills, rules of etiquette, ritual forms of interaction, etc.) components of difficult pedagogical communication.

The professional activity of teachers working in residential institutions is a special type of social activity aimed at transferring experience, knowledge and skills from older generations to younger ones, coupled with taking into account the specifics of the contingent of trainees and social factors and learning conditions. High emotional tension activities in this category of teachers is connected with the peculiarities of the contingent, increasing numbers of stress factors of professional activity: work overload, lack of role certainty, variability in the social assessment activities of the teachers working in residential care, the emotional intensity activities, which leads to increased irritability, overexcitement, anxiety, nervous breakdowns, the need to interact with particular social groups and so on[3;4]. The stressful factors of activity of teachers working in institutions of boarding type can be attributed to the specifics of their activities, which involves full involvement in the process of interaction with pupils of boarding houses, irregular work schedule, constant exploitation of their communicative, expressive, organizational skills, information overload, increased emotionality of working situations [5].

Frequent negatively charged emotional States, which tend to accumulate, lead to a decrease in frustration tolerance and the formation of a syndrome of emotional burnout, which tends to increase with the increase in the length of service of teachers working in residential institutions. As a result, there is dissatisfaction with the teaching profession, loss of ambition and emotional exhaustion [5].

Communication in the context of interaction of various pedagogical subsystems sometimes acquire the character of difficult for a number of reasons, first of all, against the background of regular exposure to stress factors, the teacher increases the likelihood of "burnout syndrome", the manifestations of which include: fatigue, lack of strength, low performance, various symptoms of physical ailments (headaches, insomnia, problems of the gastrointestinal tract, heart disease, etc.), a sense of "muffled", dulled emotions, violation of the system of relations, formation of negative attitudes towards yourself, work, students. Thus, the main stress factors of pedagogical activity are primarily the difficulties associated with pedagogical communication.

Currently, behavioral coping strategies (coping strategies) are actively studied, describing the characteristic ways of human behavior in different situations, which are a stabilizing factor that helps a person to maintain psychosocial adaptation during periods of stress, which have two vectors of implementation: focus on the problem, which allows to destroy the stressful relationship of the individual and the environment and focus on emotions aimed at managing emotional distress [6].

The basis for the allocation of classification features of coping strategies are two vectors that determine the direction of the subject's efforts to solve the problem: 1) the problem 
itself - problem-oriented coping; 2) to change their own attitudes and assessments emotionally-oriented coping [6].

An interesting approach is S. Hobfall, which proposes a multi-axis model, which is based on the idea of overcoming behavior as a leading strategy of human behavior, which has two main axes: prosocial-antisocial and active-passive, as well as one additional axis (direct - indirect). Based on the proposed scheme, the author identifies several interaction strategies: active, prosocial-contact, prosocial-supportive, passive cautionary, passive avoiding, direct, manipulative, antisocial, aggressive [7, 442-444]. It is this model that served as the basis for our study of the leading coping strategies of teachers working in residential institutions.

The psychological purpose of behavioral coping is to adapt a person to the requirements of the situation through the mastery, weakening or mitigation of these requirements, which levels the stressful impact of the situation.

In order to increase the adaptability to the requirements of the professional situation of teachers working in residential institutions, we conducted a study to identify their preferences in the choice of coping strategies (coping strategies) in a stressful situation, which is manifested in the success of overcoming difficulties in situations of difficult pedagogical communication.

Characteristics of the sample. The study involved 2 groups of teachers: 1) experimental group - teachers GKOU RO Rostov boarding school No. 42, GKOU RO Rostov boarding school № 48, and teachers of children's home No. 4 of Rostov-on-don in the amount of 45 people in the ages of 22 and 59 years, with experience from 4 to 37 years of age; 2) control group - teachers MOU SOSH № 81 and 94, MBOU Gymnasium No. 46 in number of 45 persons aged $21-59$ years, with work experience from 2 to 36 years. A total of 90 people took part in the study.

In both groups, there is an increase in symptoms of emotional combustion, and the maximum value falls on the stage of exhaustion. The differences between the indicators of the intensity of emotional combustion in the two groups of respondents with the preference of the experimental group are statistically significant $(\mathrm{t}=2.43$, with $\mathrm{p}=0.02)$.

The formation of the phase of "tension" in both groups is characterized by the mental state of the employee, due to the anticipatory orientation to the unfavorable development of events and is accompanied by uncomfortable sensations associated with dissatisfaction with themselves and working relationships. But the emotional component is added to the state of operational tension, which allows to perform activities qualitatively, which is manifested by the expression of the negative mode of behavior, accompanied by a brittle motivational structure of activity, leading to a decrease in the efficiency of activity and to its disorganization.

The phase of resistance is represented by selectivity of emotional response, emotional and moral professional disorientation, reduction of emotions, etc., and in both groups has a pronounced formation.

The exhaustion phase involves personal and emotional detachment, emotional deficits and the development of psychosomatic disorders and tends to increase.

Thus, in both groups, the indicators of the formation of the emotional combustion syndrome are presented in full with the preference of the experimental group towards the severity of each phase.

The next task of our study was to study coping behavior in stressful situations in teachers of both groups. It was found that teachers working in residential institutions, most often in stressful situations are prone to pronounced emotional reactions, impulsive behavior, or switch attention to something else (sub-scale "distraction - avoidance"). In a tense situation, respondents choose the impulsive emotional reaction, instead of solving the problems encountered, and also rarely choose a substitute action to shift attention and 
lessen the importance of the experiences (the subscale social distraction). That is, the respondents of the experimental group often choose a strategy of emotional involvement in the situation, or use various forms of avoidance.

Respondents of the control group tend to choose coping strategies in stressful situations. Almost all average group indicators are close to the average level.

In contrast to the respondents of the control group, the majority of respondents of the experimental group choose emotionally-oriented coping, which indicates the low stress resistance of teachers, the inability to cope with emotions in the workplace and the forced need to seek psychological support.

Quite often, representatives of the experimental group turn to coping avoidance, thereby driving the problem inside, which subsequently entails pronounced reactions, not always in terms of severity adequate situations.

In the experimental group, the strategies of social contact (26), avoidance (24) and aggressiveness (22) were most pronounced. The average severity of indicators refers to the scales of social support search (23), impulsive actions (19), indirect actions (17).

Interpreting the data obtained in accordance with the Hobfall model, where models of overcoming behavior are characterized by three intersecting coordinate axes of overcoming behavior of the individual in situations of problem communication in the system " man-man "(include the direction of action and individual activity of the subject), it can be stated that coping strategies chosen by teachers working in residential:

- on the prosociality-asociality axis: prevalence of prosocial strategies using models of social contact and search for social support. However, the respondents of the experimental group are characterized by aggressive behavior model;

- on the activity-passivity axis: a high degree of severity is inherent in such an unconstructive coping model as avoidance;

- on the axis of direct-indirect action: dominated by impulsive actions, characterized by medium severity with a tendency to maximize the manifestation of emotional response to a stressful situation.

Thus, the coping strategies chosen by the respondents of the experimental group in the situations of problem communication are prosocial, passive, direct with the use of models of social contact and search for social support, avoidance or impulsive response.

Indicators of the choice of coping strategies of the control group were distributed by levels. High level-seeking social support (25), impulsive actions (20), indirect actions (25) and aggressiveness (23). The average severity of the experimental group indicators: assertiveness (22), cautious actions (22), avoidance (16). Low level or non-typical for this group of respondents coping behavior patterns - antisocial actions (14) and social contact (21), i.e. respondents in coping with a stressful situation will not look for opportunities to interact with other people or violate the rules of behavior in society.

In accordance with the scheme of analysis proposed By S. Hobfall, it was found that coping strategies chosen by teachers working in General institutions are different:

- axis prosocialist - asocial: selected as prosocial and antisocial models of response. In particular, respondents are more likely to seek social support and rarely enter into social contact on their own, however, they react aggressively to the situation, which is protective in nature;

- on the axis of activity-passivity: a high degree of severity is inherent in the constructive coping model-assertiveness, non-constructive models-caution and avoidance in the medium degree of severity. In accordance with the actual external and internal factors affecting the teacher, respondents demonstrate either an active or passive coping strategy;

- on the direct-indirect axis: both strategies are chosen by respondents as lead strategies. Teachers working in General educational institutions can impulsively react to the situation, as well as indirectly, through manipulative influences. 
Thus, the coping strategies chosen by the respondents of the control group in situations of problematic communication are variable. This is prosocial-antisocial, active, direct indirect coping using models of assertiveness, search for social support, impulsive response or manipulative action with elements of aggressiveness.

Also, the study revealed significant correlations between the symptoms of emotional combustion and the parameters of coping behavior in stressful situations in teachers of the studied groups.

In a group of teachers working in educational institutions of residential type (experimental group) the following dependencies were found:

- emotional combustion stage "tension" - passive strategy with the model of avoiding traumatic events $(\mathrm{r}=0,36(0,05))$;

- "resistance" - passive coping strategies (caution $(\mathrm{r}=0.36(0.05))$, avoidance $(\mathrm{r}=0.44$ (0.01), also choose coping focused on avoidance $(\mathrm{r}=0.36(0.05))$;

- "exhaustion" -asocial strategy (aggressiveness $(\mathrm{r}=0,47(0,01))$, passive (avoidance $(\mathrm{r}$ $=0,43(0,02))$ and direct (impulsivity $(\mathrm{r}=0,47(0,01))$, and tend to choose emotionallyoriented coping $(r=0,36(0,05))$.

Thus, teachers of the experimental group, whose indicators relate to the stage of tension, tend to use coping avoidance of traumatic events, to the stage of resistance-caution and avoidance, to the stage of exhaustion - aggressiveness, avoidance or aggressiveness in favor of emotional response.

In the group of teachers working in educational institutions of General type (control group):

- stage of emotional combustion "tension" - active strategy with the model of assertive actions $(\mathrm{r}=0,41(0,03))$ and indirect strategy with the model of manipulative actions $(\mathrm{r}=$ $0,38(0,05))$ and the choice of problem-oriented coping $(\mathrm{r}=0,4(0,04))$;

- "resistance" - prosocial (search for social support $(\mathrm{r}=0.39(0.04))$, and direct coping strategy in the form of impulsive behavior $(r=0.42(0.02))$ and the subscale "Social distraction" ( $\mathrm{r}=0.38(0.05))$;

- "exhaustion" -asocial strategy (aggressiveness $(\mathrm{r}=0.47$, with $\mathrm{p}=0.01)$ ) and emotionally-oriented coping $(r=0.41(0.03))$.

Thus, teachers of the control group, whose indicators relate to the stage of tension, are prone to assertive actions with elements of manipulativeness and propensity to solve problems, at the stage of resistance - to search for social support, impulsive response or desire to distract socially acceptable ways, at the stage of exhaustion - show aggression and demonstrate emotionally-oriented coping.

When comparing the severity of the characteristics of emotional combustion in both groups, it was revealed that the representatives of the first group had significantly higher indicators related to the stage of resistance $(U=36(0.02)$ and exhaustion $(U=52(0.01))$.

When using the style of problem-oriented coping, representatives of the experimental group use coping models of social contact $(\mathrm{r}=0.37(0.05))$ and the search for social support $(\mathrm{r}=0.41(0.03))$, i.e. the prosocial strategy of coping and the less ready to display aggressiveness $(\mathrm{r}=-0.45(0.01))$ and impulsivity $(\mathrm{r}=-0.36(0.05))$.

Thus, the replacement activity of the respondents is characterized by a high emotional background of the reaction of the situation, but directed at another object.

When using the strategy of problem-oriented coping, representatives of the control group tend to use coping of confident behavior $(r=0.43(0.02))$, impulsivity $(r=0.37$ $(0.05))$ with elements of aggressiveness $(r=0.42(0.03))$, i.e. prosocial, antisocial and direct coping strategy. According to Hobfall, this combination of coping models indicates successful coping with professional stress. 
When using the style of emotionally-oriented coping, teachers of group 2 use coping models of searching for social support $(r=0.4(0.03))$ and manipulative actions $(r=0.37$ $(0.05))$, - prosocial and indirect coping strategies.

When using coping focused on avoidance, representatives of the control group use coping models of manipulative actions $(r=0.41(0.03))$ and caution $(r=0.42(0.03))$, i.e. use passive and indirect coping strategies. The choice of these models when using the avoidance strategy is also typical for the representatives of the experimental group.

The more representatives of group 2 use the strategy of distraction, the more often they use coping models of social support search $(r=0.39(0.04))$ and impulsivity $(r=0.37$ $(0.05)$ ), i.e. prosocial and direct strategies, which indicates a high emotional background of verbal response to a stressful situation in the presence of persons ready to provide emotional support.

The more often respondents are willing to use the strategy of social distraction, the more they are willing to use the model of confident behavior $(\mathrm{r}=0.36(0.05))$ and the least aggressiveness $(r=-0.46(0.01))$.

When comparing coping strategies used by respondents of both groups, statistically significant differences were obtained $(\mathrm{t}=2.71(0.001))$ in the parameters:

- social contact $(\mathrm{U}=41)$,

- search for social support $(U=53)$

- careful steps $(\mathrm{U}=44)$,

- avoidance $(\mathrm{U}=45)$,

- manipulative actions $(\mathrm{U}=42)$.

Thus, the study found that almost all representatives of the study groups in varying degrees represented radical emotional burnout.

The formation of the "stress" phase in both groups is characterized by the mental state of the employee, due to the anticipation of adverse developments, accompanied by a feeling of General discomfort, dissatisfaction with oneself, anxiety, depression, etc.

\section{References}

1. L.M. Mitina, Lichnostno-professional'noe razvitie uchitelya: strategii, resursy, riski (2018)

2. O.V. Zadorozhnaya, Trudy RGUPS, 1, 16-21 (2017)

3. O.A. Kozyreva, Sovremennaya nauka: aktual'nye problemy teorii i praktiki. Seriya: Gumanitarnye nauki, 11(12), 41-42 (2013)

4. Z. Ya. Oleksyuk, V. V. Bobrova, Zh.Kh. Kenderbekovoi, M.T. Baimukanova, Sovremennye problemy nauki i obrazovaniya, 4, (2013)

5. A.V. Loginova, Molodoi uchenyi, 11, 1750-1752 (2015)

6. W.M. Ensel, N. Lin, J. Health and Soc. Behavior, 32, 321-341 (1991)

7. N.P. Fetiskin, Sotsial'no-psikhologicheskaya diagnostika razvitiya lichnosti i malykh grupp (2002)

8. N.E. Vodop'yanova, E.S. Starchenkova, Praktikum po psikhologii menedzhmenta i professional'noi deyatel'nosti, 38, 311-321 (2001) 